\title{
Publisher Correction: Random access quantum information processors using multimode circuit quantum electrodynamics
}

\author{
R.K. Naik (1) ${ }^{1}$, N. Leung ${ }^{1}$, S. Chakram¹, Peter Groszkowski², Y. Lu' ${ }^{1}$ N. Earnest ${ }^{1}$, D.C. McKay ${ }^{3}$, Jens Koch (i) ${ }^{2}$ \& \\ D.I. Schuster ${ }^{1}$
}

Correction to: Nature Communications https://doi.org/10.1038/s41467-017-02046-6, published online 04 December 2017

In the original version of this Article, the affiliation details for Peter Groszkowski and Jens Koch were incorrectly given as 'Department of Physics, University of Chicago, Chicago, IL, 60637, USA', instead of the correct 'Department of Physics and Astronomy, Northwestern University, Evanston, Illinois 60208, USA'. This has now been corrected in both the PDF and HTML versions of the Article.

Published online: 09 January 2018

Open Access This article is licensed under a Creative Commons Attribution 4.0 International License, which permits use, sharing, adaptation, distribution and reproduction in any medium or format, as long as you give appropriate credit to the original author(s) and the source, provide a link to the Creative Commons license, and indicate if changes were made. The images or other third party material in this article are included in the article's Creative Commons license, unless indicated otherwise in a credit line to the material. If material is not included in the article's Creative Commons license and your intended use is not permitted by statutory regulation or exceeds the permitted use, you will need to obtain permission directly from the copyright holder. To view a copy of this license, visit http://creativecommons.org/licenses/by/4.0/.

(c) The Author(s) 2018

\footnotetext{
${ }^{1}$ The James Franck Institute and Department of Physics, University of Chicago, Chicago, IL 60637, USA. ${ }^{2}$ Department of Physics and Astronomy, Northwestern University, Evanston, Illinois 60208, USA. ${ }^{3}$ IBM T.J. Watson Research Center, Yorktown Heights, NY 10598, USA. R. K. Naik, N. Leung and S. Chakram contributed equally to this work. Correspondence and requests for materials should be addressed to R.K.N. (email: rnaik24@uchicago.edu) or to D.I.S. (email: david.schuster@uchicago.edu)
} 